\title{
Supporting healthy route choice for commuter cyclists: The trade-off between travel time and pollutant dose
}

\author{
Judith Y.T. Wang ${ }^{\mathrm{a}}$, Kim N. Dirks ${ }^{\mathrm{b}}$, Matthias Ehrgott ${ }^{\mathrm{c}, *}$, Jon Pearce ${ }^{\mathrm{d}}$, Alan K. L. Cheung ${ }^{\mathrm{e}}$ \\ ${ }^{a}$ School of Civil Engineering \& Institute for Transport Studies, University of Leeds, Woodhouse Lane, Leeds LS2 9JT, \\ United Kingdom \\ ${ }^{b}$ School of Population Health, The University of Auckland, Private Bag 92019, Auckland 1142, New Zealand \\ ${ }^{c}$ Department of Management Science, Lancaster University, Bailrigg, Lancaster LA1 4YX, United Kingdom \\ ${ }^{d}$ Department of Engineering Science, The University of Auckland, Private Bag 92019, Auckland 1142, New Zealand \\ ${ }^{e}$ School of Environment, The University of Auckland, Private Bag 92019, Auckland 1142, New Zealand
}

\begin{abstract}
Cyclists form the most vulnerable road user group in terms of injury from traffic accidents, as well as exposure to traffic-related air pollution. Ironically, commuter cyclists are often motivated by improvement in health and fitness. Cycleways away from traffic with lower concentrations of pollutants from motorised vehicles sometimes result in longer distances and hence require longer travel times, while alternative routes sharing the road with other traffic, sometimes with buses, might result in exposure to higher pollutant concentrations. To help commuter cyclists achieve their objectives of getting to work in the shortest possible time and maximising their health benefits, we propose a bi-objective route choice model, with the minimisation of travel time and pollutant dose as the two objectives. A transport network information database is first constructed with comprehensive information on link type, lane width, gradient, link average speed, traffic volume, etc. such that both the travel time and the pollutant dose can be estimated at a reasonable level of accuracy. In particular, the pollutant dose will be dependent on the exercise level as well as the concentration of pollutants. Given an origin and a destination, to be provided by a cyclist, we apply a bi-objective shortest-path algorithm to determine an efficient set of routes such that neither the total travel time nor the total pollutant dose can be reduced without worsening the other. Profiles of this route choice set in terms of other useful information, such as elevation, and pollutant concentrations along the route can also be provided. With our model, cyclists can more easily trade off between commute time and pollutant dose. In cities with hilly terrain, such as in Auckland, New Zealand, such information can be expected to be extremely
\end{abstract}

\footnotetext{
${ }^{*}$ Corresponding author. Tel.: +44 1524593888

Email addresses: j.y.t.wang@leeds.ac.uk (Judith Y.T. Wang), k.dirks@auckland.ac.nz (Kim N. Dirks), m.ehrgott@lancaster.ac.uk (Matthias Ehrgott), j.pearce@auckland.ac.nz (Jon Pearce), a. cheung@auckland.ac.nz (Alan K. L. Cheung)
} 
valuable for current and potential cyclists.

Keywords: Commuter cycling, optimisation, air pollution exposure, route choice, bi-objective shortest path.

\section{Introduction}

Promoting the use of more sustainable modes of transport, such as active modes including walking and cycling, has been one of the key policy instruments used to improve the sustainability of transportation systems. For example, the launch of Barclays Cycle Hire and Barclays Cycle Superhighways in 2010 in London, together with the congestion charging introduced in 2003, clearly form part of an integrated strategy to promote cycling as a mode of transport. In fact, even before the introduction of 'Cycle Superhighways', based on data collected through a set of permanent automatic cycle counters on selected sections by Transport for London (TfL), as shown in Transport for London (2010), the average flows were showing steady increases, and the average flow in 2009/10 was 117 per cent higher than in 2000/01. A trend analysis of cycle flows on major roads in London based on Department for Transport (DfT) data (Transport for London, 2010, p.58, Figure 2.12) show that the rate of increase since the introduction of congestion pricing in 2003 has been significantly higher. The number of people entering central London by bicycle during the weekday morning peak increased by 15 per cent in 2009 and more than doubled (an increase of 123 per cent) between 2001 and 2009 (Transport for London, 2010, p.58).

Cycling is no doubt a sustainable mode of transport for many reasons. To name a few, it does not consume non-renewable energy resources such as fossil fuels, it does not generate vehicle emissions that damage our environment and potentially cause negative impacts on population health, and it promotes health and fitness and general well-being. In fact, based on a survey conducted at the University of Auckland, 'to improve health and fitness' was identified as the primary motivator for existing cyclists to cycle (Wang et al., 2014). A number of review studies (de Hartog et al., 2010; Götschi et al., 2015; Oja et al., 2011; Mueller et al., 2015) have shown that cycling can indeed be part of daily life as a mode of transport and a means to improve health and fitness, with the increase in physical activity contributing dominant benefits. However, along with accident risk, increased exposure to air pollution is also of concern for cyclists (Wang et al., 2014). Road vehicles produce a range of gaseous pollutants (including carbon monoxide) and particulate matter of various size fractions, pollutants that tend to be correlated with one another when measured in roadside environments 
(Beckerman et al., 2008). Unlike the commonly-measured gaseous pollutants, particulate matter is difficult to quantify as every particle is unique in its size, shape and composition. Likewise, unlike the major gaseous pollutants, particulate matter does not have a known maximum safe exposure limit, so any reductions in exposure through the careful design of cycling infrastructure can be considered to be of health benefit. One would also expect that air pollution dose is highly variable depending on the spatial characteristics of the route.

Regional authorities typically monitor a range of different pollutants in order to assess the quality of the air. Traditionally, personal exposure studies have tended to use carbon monoxide (CO) as the marker for traffic air pollution monitoring, due to the early development of portable monitoring technology for this pollutant (De Bruin et al., 2004; Liu et al., 1994). In urban environments where there is a relatively high proportion of older petrol vehicles, $\mathrm{CO}$ remains a useful pollutant to measure (Dirks et al., 2012). Recent personal exposure studies tend to involve the measurement of multiple pollutants simultaneously, typically particulate matter (PM) as well as CO (Int Panis et al., 2010; Kaur et al., 2005). Thus, CO remains popular despite its more limited health risk at the levels typically observed in commuter exposure studies. In this study, we also use $\mathrm{CO}$ as a proxy for PM emissions, which are harder to measure using portable monitoring equipment.

There has been a strong focus in the recent literature on commuting, with respect to air pollution exposure since people tend to spend a significant amount of their outdoor time commuting and air pollution levels tend to be high along road corridors (Kaur et al., 2005). Many studies compare exposure for different modes of commuting, (e.g. de Nazelle et al., 2012; Dirks et al., 2012; Duci et al., 2003; Int Panis et al., 2010). While studies have shown that the concentrations to which cyclists are exposed tend to be somewhat lower than for those commuting by private vehicles (Boogaard et al., 2009; Rank et al., 2001), when the (often) increased commute time and increased physical activity of cyclists during their commute are taken into account, the air pollution doses have been found to be significantly higher than for the motorised modes (de Nazelle et al., 2012; Dirks et al., 2012; Int Panis et al., 2010). For instance, experimental results from studies conducted in Auckland, New Zealand indicate that while the concentrations of $\mathrm{CO}$ experienced by a runner and a cyclist are lower than that experienced by a car driver, the corresponding $\mathrm{CO}$ doses are higher (Dirks et al., 2012). Similar patterns of $\mathrm{PM}_{2.5}$ concentration and doses are observed in experiments conducted in Barcelona (de Nazelle et al., 2012).

This also means that switching from motorised vehicles to cycling might not necessarily bring 
health benefits from the point of view of air pollution exposure unless carefully designed cycleways are provided or there is a very substantial decrease in the number of cars on the roads. This has significant implications for the planning of cycling infrastructure such as 'Cycle Superhighways' and their connections to the existing network of cycling facilities. It is essential to ensure that the investment in cycling infrastructure/facilities can improve both travel time for commuters as well as creating health benefits for both cyclists and non-cyclists from the point of view of air pollution exposure.

Cycleways away from traffic and on roads with lower concentrations of pollutants from motorised vehicles are often longer routes and hence require longer travel times, while alternative routes on main roads sharing the road with other traffic, sometimes with buses, might result in exposures to higher pollutant concentrations. One would expect that the two objectives of getting to work in a reasonable amount of time (relative to commuting by other modes) while retaining the health benefits from cycling without the adverse consequences of unnecessary air pollution exposure have to be well balanced.

To assess the potential health benefits for active transport (walking and cycling), both the benefits from increase in physical activity and (dis)benefits from pollutant dose should be considered. However, pollutant dose has not been considered explicitly in most of the previous studies. As shown in Mueller et al.'s comprehensive review, only seven out of selected 30 studies have considered the impact of air pollution on active travellers (Mueller et al., 2015, Table 1). For instance, Woodcock et al. (2014) estimate a change in daily total exposure as the time spent travelling in each mode multiplied by that mode's exposure (in average concentration). While travel time has been considered, this method covers only part of the picture. As shown in experimental studies, due to a two- to threefold increase in breathing rate for active modes compared to passive travel modes, this method might lead to underestimation of inhaled pollutant dose. As shown in experimental results (de Nazelle et al., 2012), the inhaled doses of pollutants during commuting account for a high percentage of the total daily dose, e.g. $\mathrm{CO}$ intakes account for $40-65 \%$ for all modes. It is, therefore, important to assess the health impact of inhaled pollutant dose during commuting.

Another aspect that is missing in the assessment is the localised (spatial) effect of changes in level of congestion. For instance, Woodcock et al. (2009) developed an Integrated Transport and Health Impact Modelling Tool (ITHIM) to estimate the health impacts from transport related physical activity as well as changes to air pollution. However, the effect of changes in traffic congestion on air pollution was not modelled in ITHIM. It is assumed that the reduction in transport-related emissions, as a result 
of increases in walking and cycling instead of car use, led to equal proportional reduction in pollutants attributed to transport. Schepers et al. (2015) assess the potential health impact of investment in cycling infrastructure in a hypothetical city considering both the influence of changes in physical activity and pollutant dose. However, the assessment is based on change in mean concentration and the effect of travel behavioural change in terms of modal shift from driving to cycling is not modelled.

To model the influence of traffic volume, composition and speed on the environment, there are numerous studies in the literature linking strategic transport planning models with air quality models, e.g. Affum et al. (2003); Boogaard et al. (2012); Hatzopoulou and Miller (2010); You et al. (2010); Lee et al. (2009). Vehicle emissions are first estimated based on link-based traffic flow, speed and vehicle types. Then by applying dispersion models, pollutant concentrations can also be estimated. In order to assess health effects of emissions, recent studies have taken one step further to assess individual exposure to air pollution (Shekarrizfard et al., 2015; Sider et al., 2013), where exposure is modelled by a proxy variable as the level of emissions occurring in a zone. Hatzopoulou et al. (2013) developed a web-based route planning tool to help cyclist find the 'cleanest' route based on lowest exposure in Montreal, Canada. Exposure is measured by multiplying the estimated average $\mathrm{NO}_{2}$ concentration of a road segment, using calibrated traffic assignment and emission models, with its length. This measure is effectively a proxy variable represented by a mathematical expression of the integrated concentration of $\mathrm{NO}_{2}$ over the entire route. Individual inhaled pollutant dose has not been modelled explicitly.

In this study, we propose a bi-objective route choice model that can be used to provide information to help commuter cyclists achieve their objectives of getting to work efficiently while maximising their health benefits. From a modelling point of view, this is also a fundamental step in developing methodologies for the assessment of the economic, environmental and health benefits of cycling infrastructure investment and cycling facility improvement projects.

\section{Problem Formulation}

To help cycling trip planning, we propose a bi-objective route choice model, which minimises travel time and pollutant dose, the two objectives in the bi-objective routing problem.

\subsection{Objective 1 - To minimise travel time}

In Ehrgott et al. (2012), the assumption was made that cyclists travel with fixed velocity across the whole network and therefore, a cyclist travel time function was adopted which is based purely 
on distance travelled. In reality, for cities other than those that are completely flat, the speed (and therefore the travel time) of cyclists is affected by hills. In this paper, we make the assumption that, when faced with non-level terrain, a cyclist adjusts their speed so that their level of physical exertion remains constant, and their travel speed changes to compensate for the gradient. Hence, we introduce a travel time function for cyclists,

$$
t_{a}=\frac{l_{a}}{\bar{v}_{a}},
$$

where $t_{a}$ is the travel time on link $a ; l_{a}$ is the length of link $a$; and $\bar{v}_{a}$ is the average speed travelled along link a, given by

$$
\bar{v}_{a}=\bar{v}_{0}-\theta \times \bar{s}_{a},
$$

where $\bar{v}_{0}$ is the average speed in a flat terrain; $\theta$ is the adjustment factor for the gradient; and $\bar{s}_{a}$ is the average gradient of link $a$. We define $\bar{s}_{a}$ to be negative when the commuter is travelling downhill and positive when the commuter is travelling uphill. In flat terrain, $\bar{s}_{a}$ equals zero, hence $\bar{v}_{a}=\bar{v}_{0}$.

As time is additive, the total travel time on route $p$ is simply the sum of the travel times on the links along the route,

$$
t_{p}=\sum_{a \in p} t_{a} .
$$

\subsection{Objective 2 - To minimise pollutant dose}

We adopt a three-stage approach to modelling the pollutant dose by the cyclist during their commute. This involves: (a) modelling the emission rates for the road for each link based on the traffic flow, the average vehicle speed and the vehicle fleet composition; (b) modelling the air pollutant concentrations from the road emission rates and the surface meteorology; and (c) modelling the cycling commuter dose from the air pollution concentrations and the travel time along each link in the commute. Each stage is described in turn below.

\subsubsection{Stage 1 - From traffic flow, speed and composition to vehicle emissions}

In order to estimate the road emission rates, we adopt the results from Costello et al. (2012). Costello et al. obtained traffic assignment outputs comprising speeds, volumes and vehicle fleet composition on each modelled network link from the Auckland Regional Transport Planning Model 
(known as ART3), provided by the former Auckland Regional Council (ARC). They combined this information with the Vehicle Emissions Prediction Model (VEPM), originally developed by the University of Auckland for ARC (Auckland Regional Council, 2008). The VEPM predicts the emission rates of (single) vehicles found in the New Zealand fleet for typical road, traffic and operating conditions. Application of the VEPM to the traffic data from ART3 allowed them to estimate tailpipe emission rates for $\mathrm{CO}$, carbon dioxide, oxides of nitrogen, particulate matter and volatile organic compounds for passenger cars, light duty and heavy duty vehicles. These were calculated for each link for three periods during the day corresponding to the AM peak (7:00am-9:00am), inter-peak (9:00am-3:00pm) and the PM peak (4:00pm-6:00pm) for weekdays, as modelled in ART3. From this, we obtained the total vehicle emission rate of pollutant $x$ on each link, $Q_{a}^{x}$ for each of the three time periods of interest.

\subsubsection{Stage 2 - From vehicle emissions to pollutant concentrations}

Here we adopt the Site-Optimised Semi-Empirical (SOSE) model as described in Dirks et al. $(2002,2003)$ to predict the air pollution concentrations from the road emission rate and the average wind speed,

$$
C_{a}^{x}=\frac{Q_{a}^{x}}{\Delta z\left(u+u_{0}\right)}+C_{B}^{x},
$$

where $C_{a}^{x}$ is the estimated concentration of pollutant $x$ on along link $a ; Q_{a}^{x}$ is the total emission level of pollutant $x$ on link $a$; and $\Delta z, u, u_{0}, C_{B}^{x}$ are calibrated model parameters. The parameter $\Delta z$ is the 'box height' defined as the height of a box above the road into which pollutants are assumed to be uniformly mixed, $u$ is the horizontal wind speed, $u_{0}$ is the wind speed offset, included to avoid unrealistically high pollution concentration predictions in periods of very low wind speeds, and $C_{B}^{x}$ is the background concentration.

\subsubsection{Stage 3 - From pollutant concentrations to pollutant dose}

Here we adopt the approach proposed by Dirks et al. (2012) to predict the dose of pollutants (relative to a passive commuter) based on the air pollution concentration along a link, the time spent travelling on a link and the breathing rate of the cycling commuter.

$$
d_{a}^{x}=C_{a}^{x} \times t_{a} \times \bar{\beta}_{a},
$$


where $d_{a}^{x}$ is the relative dose of pollutant $x$ along link $a$; $t_{a}$ is the travel time on link $a$; and $\bar{\beta}_{a}$ is the average cyclist minute ventilation along link $a$.

As stated above, here we assume that the average minute ventilation $\bar{\beta}_{a}$ is unaffected by the topography; that the cyclist simply adjusts their travel speed in such a way that their minute ventilation remains constant for links of differing slopes. Hence,

$$
\bar{\beta}_{a}=\alpha_{a} \times \beta_{0},
$$

where $\alpha_{a}$ is the adjustment factor for cycling; and $\beta_{0}$ is the resting minute ventilation.

Since dose is also an additive function, the total dose for route $p$ is simply the sum of the dose on each link along the route,

$$
d_{p}^{x}=\sum_{a \in p} d_{a}^{x}
$$

\section{Parameter Estimation}

\subsection{Average commuting speed}

The bi-objective model requires an estimate of the average bicycle commuter speed. One of the most comprehensive surveys of average commuter speed was carried out by Aultman-Hall (2004) in which a questionnaire was administered to over 3000 commuter cyclists in Ottawa and Toronto, Canada, both of which are essentially flat cities, and found the average cyclist commuter speed to be approximately $(19 \pm 5) \mathrm{km} / \mathrm{h}$ and $(15 \pm 5) \mathrm{km} / \mathrm{h}$ in each of the cities, respectively. Based on these results, it is assumed here that the cyclists travel at an average speed of $17 \mathrm{~km} / \mathrm{h}$ in level terrain.

\subsection{Relationship between cycle speed and road gradient}

In the bi-objective model, as stated above, it is assumed that, when faced with a slope (either positive or negative), a cyclist will adjust their commute speed so that their level of physical exertion remains constant throughout their journey. Martin et al. (1998) found that, for racing cyclists, for a given road gradient, the adjustment factor, $\theta$, as defined in Equation (2), for the road gradient was 4.5 $\mathrm{km} / \mathrm{h}$, with the average road gradient, $\bar{s}_{a}$, expressed as a percentage. These values are assumed here. The relationship was found to be linear for road gradients in the range of $-6 \%$ to $+6 \%\left(R^{2}>0.99\right)$ (Martin et al., 1998). 
For the present study, the road gradient is restricted to the range of $-6.00 \%$ to $+2.55 \%$. A value of $-6.00 \%$ corresponds to a travel speed of $45 \mathrm{~km} / \mathrm{h}$, a reasonable maximum speed for a cyclist travelling in traffic. A slope of $+2.55 \%$ corresponds to a travel speed of $5 \mathrm{~km} / \mathrm{h}$, a typical walking speed. For any slope steeper than this, one can reasonably expect the cyclist to get off their bicycle and walk up the hill rather than persist on their bicycle at slower speeds.

\subsection{Box height, wind speed offset and wind speed}

An observational air quality field campaign was carried out in Auckland during the winter of 2010 (Longley et al., 2013). Based on the data collected, the average box heights were found to be $60 \mathrm{~m}, 120 \mathrm{~m}$ and $260 \mathrm{~m}$, and the average wind speeds over a period of three months were found to be $2.1 \mathrm{~m} / \mathrm{s}, 3.5 \mathrm{~m} / \mathrm{s}$ and $2.5 \mathrm{~m} / \mathrm{s}$, for the AM peak, inter-peak and PM peak periods, respectively. The values are assumed to be applicable across Auckland and be representative of winter conditions. In the immediate vicinity of a road, it may be reasonable to assume that the contribution of the background to the overall concentration is negligible.

\subsection{Breathing rate}

The minute ventilation (the product of the breathing rate and the volume of air per breath) of cyclists is required to calculate the dose of pollutants. Studies have suggested that while commuting via sedentary modes, such as by car, the minute ventilation of an adult is around $12 \mathrm{~L} \mathrm{~min}^{-1}$. Studies have suggested that this value increases by a factor of two to four for cyclists, depending on the level of physical exertion (Int Panis et al., 2010; Zuurbier et al., 2009). In this study, it is assumed that $\alpha_{a}=3$ and $\beta_{0}=12$ in Equation (6), leading to an average minute ventilation of $\bar{\beta}_{a}=3 \times 12=36$ $\mathrm{L} \min ^{-1}$, which is not dependent on the link.

\subsection{Limitations of the model formulation and parameter selection}

The average commuting speed of cyclists will vary significantly from person to person depending on many factors including the commuter's level of fitness, age and gender, and will also vary from place to place because of cultural differences and attitudes to cycling and transport infrastructure. The parameter estimates suggested here are based on data collected for two Canadian cities and may not be representative of other cities around the world. At the present time, there is little information about average commuter cycling speed for Aucklanders. 
The model assumes that the cyclists adjust their speed in response to gradients in such a way that their level of physical exertion remains constant throughout their commute and that their minute ventilation is three times that of a passive commuter. This is not necessarily the case; minute ventilation will be highly variable depending on the level of physical exertion of the cyclist. Also the slope of the line relating the cycling speed to the slope needed to maintain a constant level of physical exertion was determined using racing cyclists (travelling at approximately $40 \mathrm{~km} / \mathrm{h}$, more than twice the commute speed assumed here). More data are needed to validate the applicability of this assumption for commuter cyclists.

The average box height estimates were made based on observations from a three-month-long field campaign carried out in Auckland during the winter. There are a number of assumptions that needed to be made in arriving at these estimates, including that of a uniform distribution within the air mass above the road, that the box heights are consistent across all of Auckland and that they apply equally to areas of different land use and road types. In reality, the box heights (and wind speed) estimates are expected to vary considerably from day to day, season to season and also to some extent from year to year. Further work is needed to determine the variability in these estimates, both spatially and temporally.

It is also important to note that accident risk and exercise benefits also need to be taken into consideration when comparing the health impacts of different modes of commuting. However, neither of these is considered here.

\section{The Bi-objective Route Choice Model}

\subsection{An overview}

The concept of the bi-objective route choice model is illustrated in Figure 1. Based on the two objectives as specified in Section 2: (1) minimise travel time; and (2) minimise pollutant dose, we apply a bi-objective shortest-path method to determine efficient routes for a given origin-destination pair. For example, as illustrated in Figure 1, Route 8 is dominated by Route 2 since both the travel time and the pollutant dose on Route 8 are higher than on Route 2 . Route 6 is dominated by Route 5 because even though both routes have the same travel time, the pollutant dose on Route 6 is higher than that on Route 5. In this way, the set of efficient routes will become a natural choice set for a cyclist, whereby neither of the two objectives can be improved without worsening the other. 


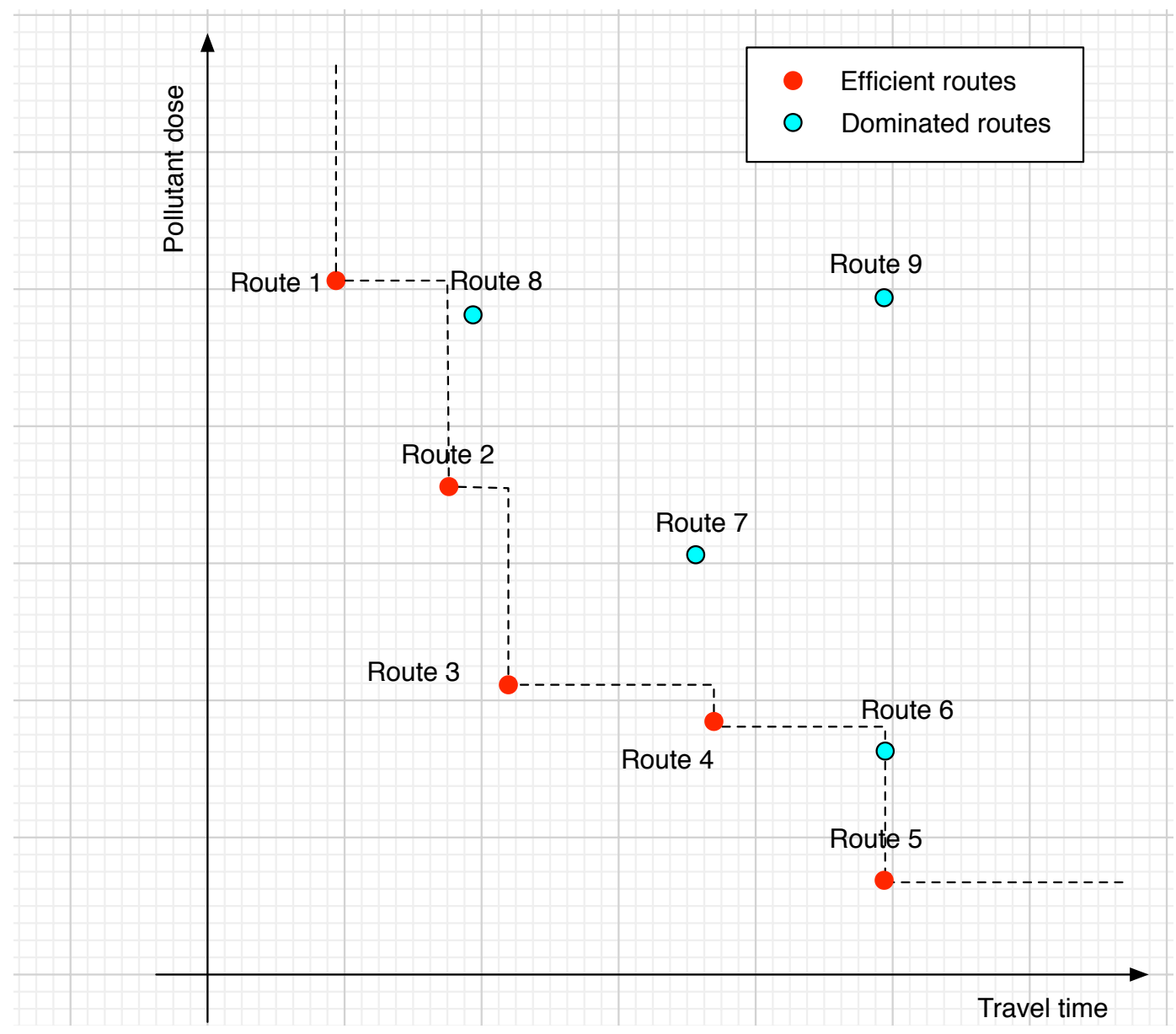

Figure 1: An illustration of the bi-objective route choice model concept 
The bi-objective shortest path-problem of finding all efficient paths from an origin to a destination is a well-known extension of the standard shortest path problem in Operations Research literature. It is known that the problem is NP-hard and that, in the worst case, the number of efficient paths can be exponential in the number of nodes (see references in Raith and Ehrgott (2009)). Despite such negative theoretical results, applications of the bi-objective shortest path problem in transport show that, in practice, the number of efficient paths is reasonably small, even in huge networks (MüllerHannemann and Weihe, 2006) and that it can be solved quickly when both objectives are additive, as in our model. Bi-objective label setting and label-correcting algorithms perform well in that case, as experiments by Raith and Ehrgott (2009) have shown. The same paper also gives an overview of other solution techniques. We employed the bi-objective label correcting algorithm, which is a straightforward extension of the standard bi-objective label correcting algorithm (Bellman, 1958). The main difference in the bi-objective algorithm is that label sets rather than single labels have to be kept at each node of the network. Initially, the source node $s$ is labelled with set Labels $(s)=\{(0,0)\}$. All labels at a particular node $i$ are extended along all outgoing $\operatorname{arcs}(i, j)$. The new label set Labels $(j)$ is formed by merging the extended labels from node $i$ and the current label set at node $j$, taking care to eliminate dominated labels. Whenever the label set of a node changes, the node has to be marked for reconsideration. At reconsideration, the mark of the node is deleted. The algorithm terminates as soon as no nodes are marked for reconsideration.

An alternative approach could be to compute only supported efficient paths to obtain an indication of the trade-off between travel time and pollutant dose. This can be done efficiently as shown by Medrano and Church (2015). If necessary further non-supported efficient paths can be found using a two-phase approach as indicated in Raith and Ehrgott (2009). In general, the problem of selecting a subset of efficient paths to present to the commuter cyclist is one that deserves further attention.

\section{A Case Study}

\subsection{The study area}

We obtained two datasets from Auckland Council. As described earlier, the traffic flow, average speed and vehicle fleet composition were obtained from the ART3 model. In this study, we focus on the AM peak as modelled in ART3, which is the period from 7am to 9am. In addition to that, a Geographic Information System (GIS) dataset with gradient information is required in order to be able to derive the appropriate speed/breathing rate adjustment. While the ART3 dataset covers 
the Auckland region, the GIS dataset includes only the Auckland City area (formerly governed by Auckland City Council). This area covered by both datasets becomes the study area of our case study. We then applied our bi-objective route choice model to two origin-destination pairs about 7 to 10 $\mathrm{km}$ apart (based on the shortest route), as shown in Figure 2, to obtain the set of efficient paths for each O-D pair. 


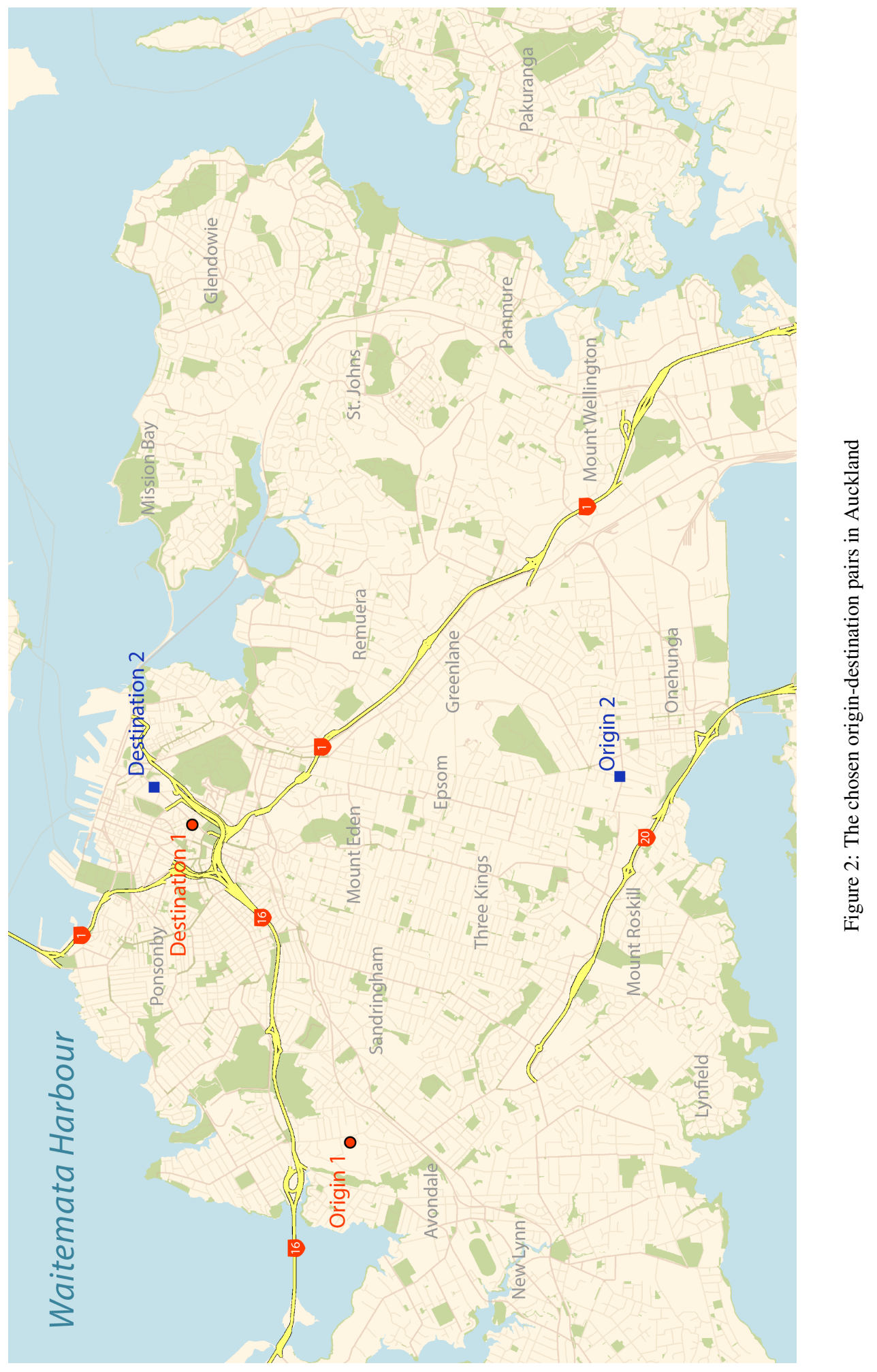




\subsection{Data preparation and manipulation}

Two main data sets are used in this analysis: The ART3 topological network assimilated to a GIS model and a GIS based gradient dataset derived from a digital elevation model. Some data manipulation was needed to create a usable road network in GIS. Our route choice model is based on a network model. The network structure is basically the road network in the traffic assignment component of the ART3 model, with approximately 16,000 links, which covers the whole Auckland region. Since the ART3 network is purely topological (non-spatial) in nature, it is necessary to assimilate its links and attributes with a GIS-based road network provided by Auckland Council in order to generate results with a spatial dimension. This was done by matching the IDs of links in ART3 with those of the roads. A combination of nearest node analysis and manual manipulation was used to handle links that were not automatically matched. The introduction of the spatial dimension is necessary for accurate extraction of gradient information.

The gradient dataset is produced from a LiDAR derived digital elevation model with a resolution of $10 \mathrm{~m}$ in the horizontal and $0.5 \mathrm{~m}$ in the vertical dimensions provided by Auckland Council. Gradient data are retrieved along each of the routes in the road network on a per-10m basis.

\subsection{Results}

There are 20 and 17 efficient routes between O-D pairs 1 and 2, respectively. The performances in terms of the two objectives are plotted in Figures 3 and 4, respectively.

Five out of the 20 and 17 efficient routes are selected for display purposes. To select these five paths, we divide the range of travel times among all efficient paths into equal intervals, and picked one from each interval.

In this way, we guarantee that the shortest path as well as the path with lowest CO dose are included in the selection, along with representatives from the bigger clusters of points in Figures 3 and 4. Figures 3 and 4 clearly illustrate the trade-offs between travel time and $\mathrm{CO}$ dose: Between Choice 5 and Choice 1, travel time roughly doubles, whereas $\mathrm{CO}$ dose approximately halves. The elevation and $\mathrm{CO}$ concentration profiles of the selected routes are illustrated in Figures 5 to 8. These figures also show the commuter's route before consideration of the bi-objective model on the maps. Based on the profiles, a cyclist will be able to select an appropriate route based on his/her own preferences. For instance, a cyclist might prefer Choice 1 over Choice 5 for OD-pair 1 to avoid going through high CO concentration areas, which can be identified from the $\mathrm{CO}$ concentration profiles illustrated in Figure 
6, although the travel time will be longer. Information on the corresponding vertical profiles of Choice

1 versus Choice 5 as provided in Figure 5 might also be used to support the route choice decision. 

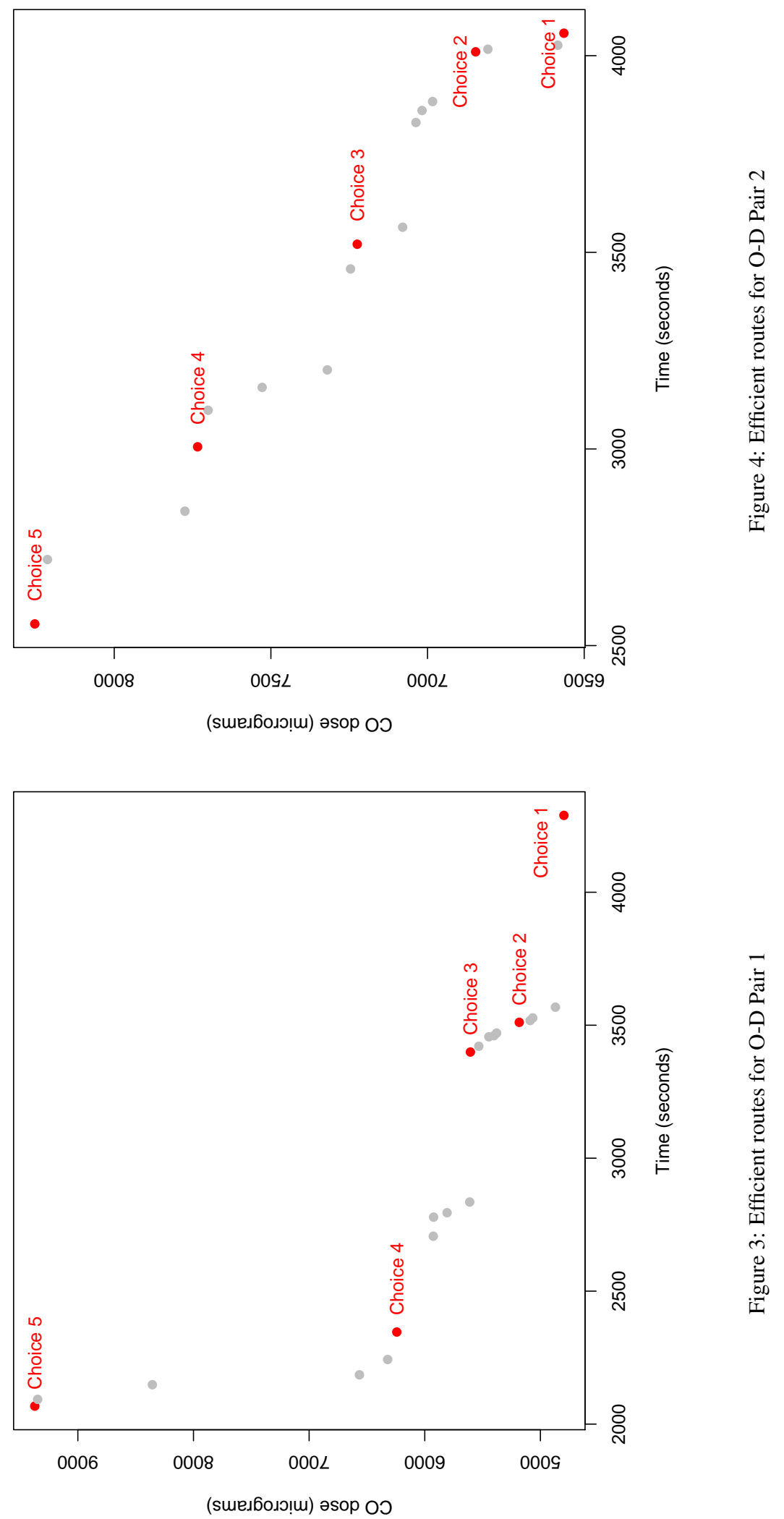


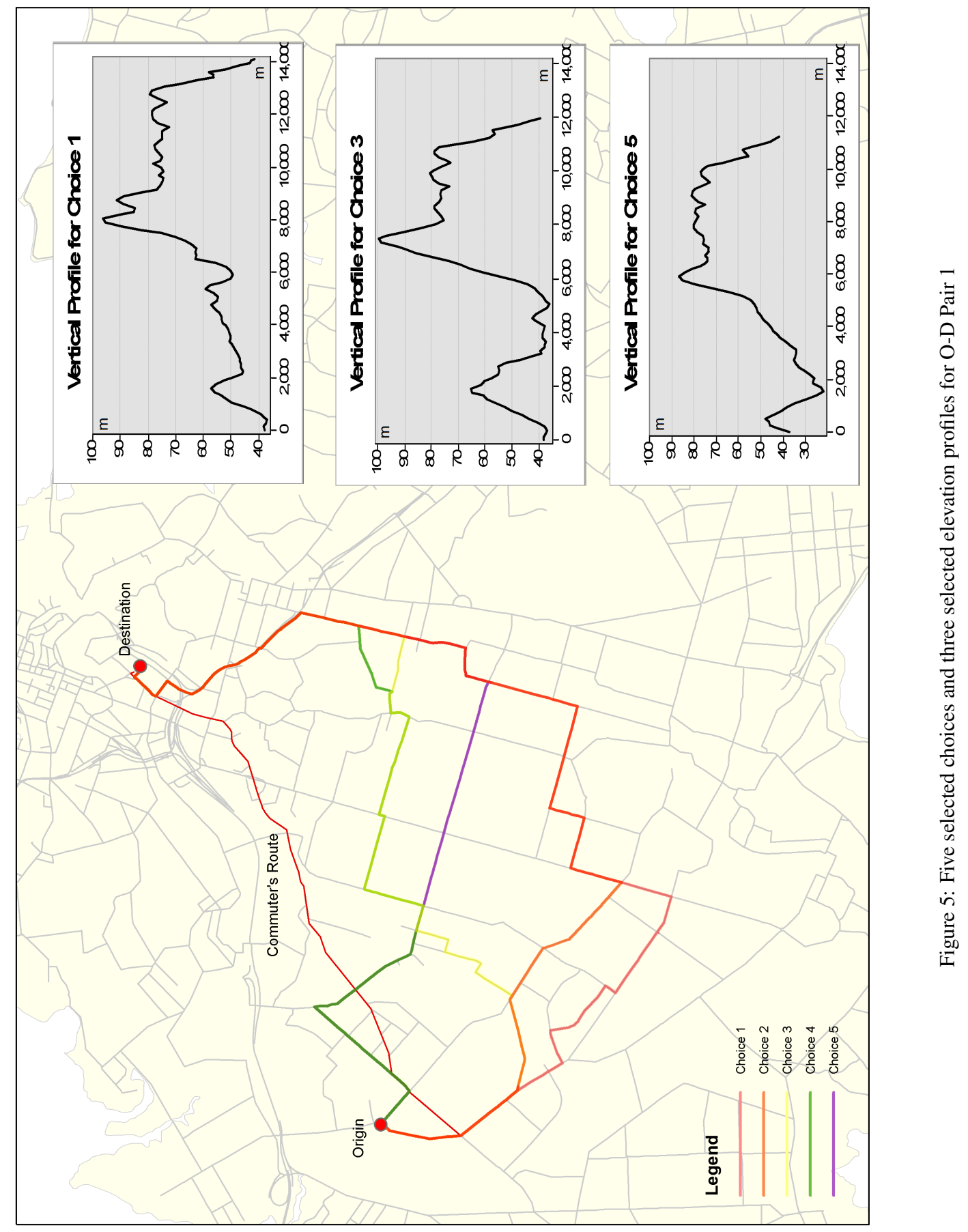




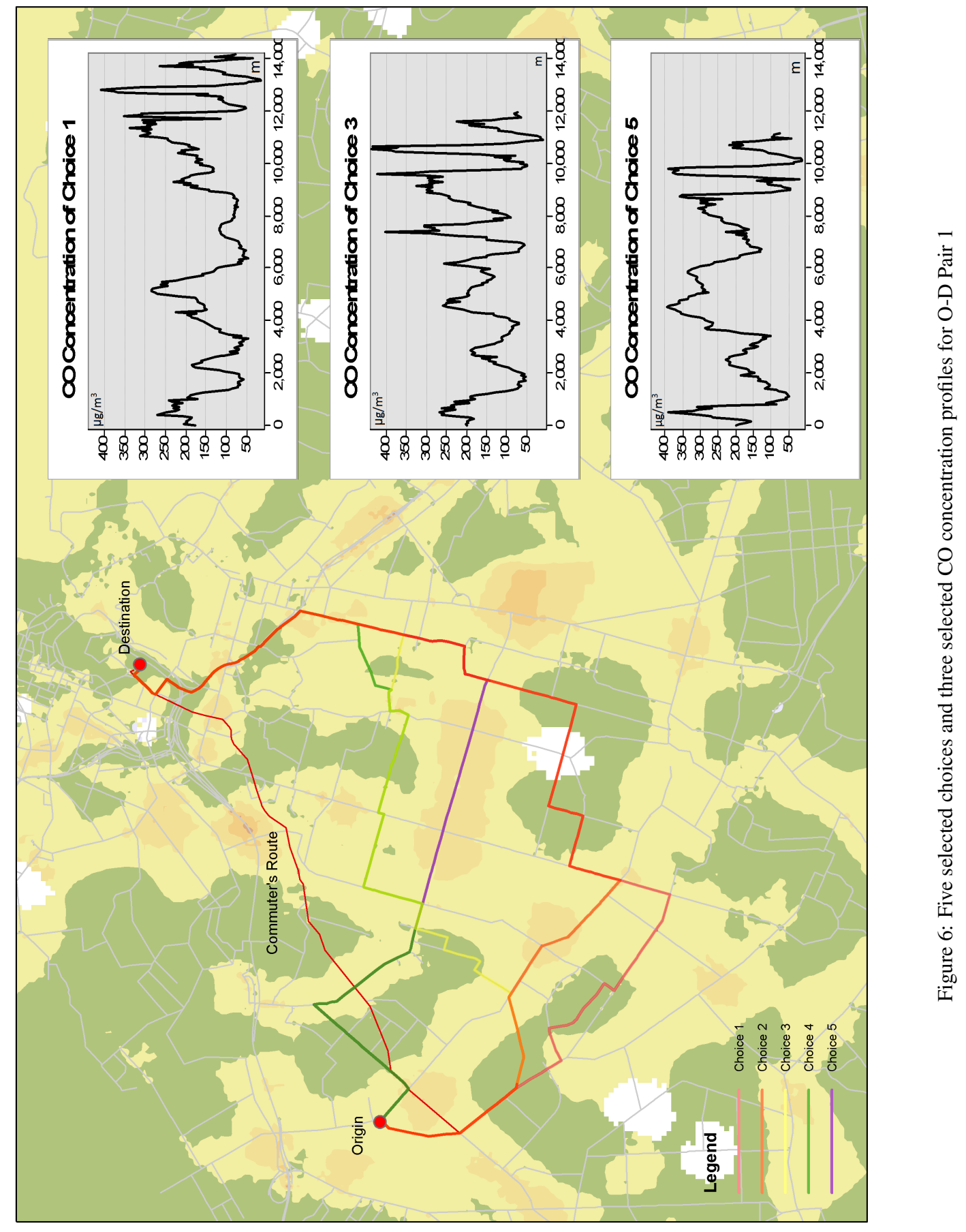




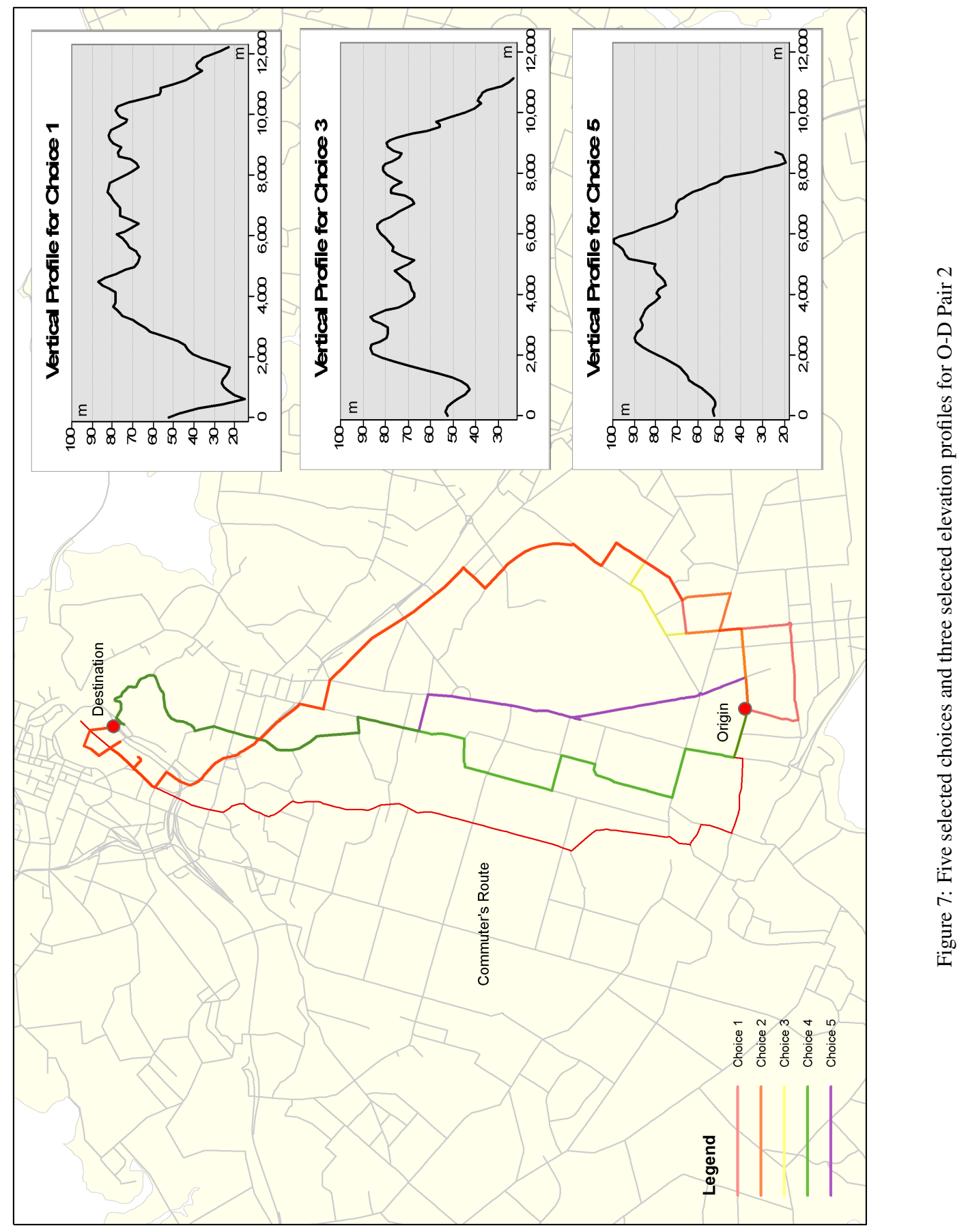




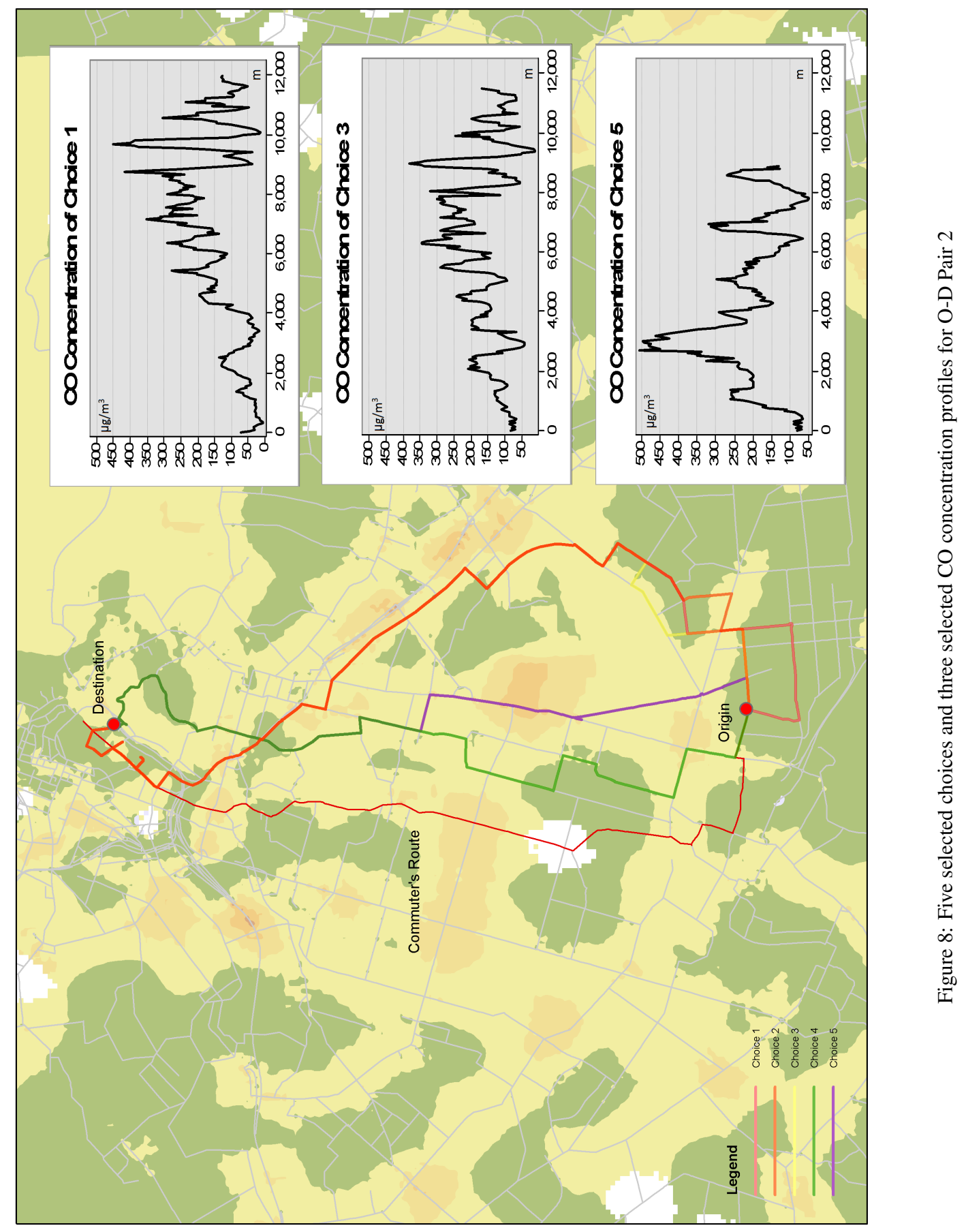




\section{Conclusions and Suggestions for Further Research}

We propose a new bi-objective route choice model to support the analysis of the health impact of route choice on cyclists. This advances the existing modelling methods to a new level. More specifically, this provides a first cut at estimating the route-specific relative dose of vehicle air pollution of individual cyclists, taking into account all of the factors (travel time, breathing rate and pollutant concentrations) contributing to this dose.

The introduction of a bi-objective method enables more comprehensive information provision, as compared with existing single objective approaches. For instance, Hatzopoulou et al.'s web-based route planning tool provides two optimised routes, one being the 'shortest' while the other being 'cleanest'. Note that the two routes are generated based on either one of the two objectives: (1) minimise distance; and (2) minimise exposure. With the proposed model, by applying a bi-objective approach, an efficient choice set can be presented to a cyclist, which will enable trade-offs between the two objectives to be made.

The proposed model also enables spatial analysis of the localised effect of changes in traffic congestion, and its subsequent effect on inhaled pollutant dose. This will take the existing aggregate approach in health impact assessment to the next level. With further research in modelling cyclist route choice behaviour, e.g. with a cyclist trip assignment model, the proposed model can be applied to estimate cyclist route-specific pollutant dose on different cycling facilities, as a result of cycling infrastructure investment such as the case study in Schepers et al. (2015). Individual doses can then be estimated on their chosen routes, which is not possible with the current approach, i.e. based on average concentration and average time spent on different infrastructure.

This model can become a building block of a decision support system to aid both policy and personal transport mode or route choice decisions. The relationship between transport choices and health needs to be studied scientifically to enable more sustainable decisions to be made. Our ultimate goal is to help maximise the benefits from cycling infrastructure and facility improvement investments, facilitating the entire system to move towards economic, environmental and health sustainability. Our approach is to build the linkages of strategic transport planning with air quality models, and subsequently assess the impact of air quality on individual cyclists at a route level such that the health impact, in terms of inhaled pollutant dose, can be assessed at an individual level.

In order to see the complete picture, other modes of transport also need to be studied. With further research, the methodology developed in this paper can be extended to conduct analysis in a 
multi-modal environment to assess the impact of the use of other alternatives modes or a mixture of different modes on population health.

Apart from the travel time and pollutant dose, safety is another important factor affecting cyclists' route choice. The model developed in this study can be extended to a multi-objective route choice model by including other important factors, including safety considerations. This will, however, increase the number of paths, as numerical studies on multi-objective shortest path problems have shown, see e.g. Paix̃ao and Santos (2013).

It is important to note the limitations of the proposed model. By adopting a network approach, we are essentially modelling an 'average' case, in the sense that traffic assignment is typically performed for the peak periods (AM and PM peaks). In other words, this is a macro approach, where the average traffic flow and speed for the modelled period are considered. As a result, the estimated inhaled dose will also be an 'average' on a specific route during the modelled period. Thus, the estimates for different options or scenarios should be compared on a relative basis for the purpose of strategic analysis. Further research consisting of a sensitivity analysis of the model parameters will be useful in order to ensure that the level of accuracy is sufficient for meaningful analysis at a strategic level.

\section{Acknowledgements}

The authors would like to thank Mr John Davies of Auckland Transport for providing data from the Auckland Regional Transport Planning Model, Mr Carl Ellaway of Auckland Council for providing the spatial digital data and information support, Mr Julien Etchebarne of Département Génie Energétique et Environnement, INSA Lyon, France for his research assistance provided during his internship at the University of Auckland, and Dr Mike Florian of INRO for providing the EMME research licence to support data manipulation and analysis. This project was partially supported by a research grant provided by Thematic Research Initiative (TRI) of the University of Auckland titled Transforming Auckland: Institutional, Technological and Cultural Innovations for Sustainable Cities.

The authors also acknowledge the thoughtful responses of two anonymous reviewers that have helped to improve the paper.

\section{References}

Affum, J., Brown, A., and Chan, Y. (2003). Integrating air pollution modelling with scenario testing in road transport planning: The TRAEMS approach. Science of the Total Environment, 312(1-3), 
1-14.

Auckland Regional Council (2008). Development of a vehicle emission prediction model VEPM. Technical report, Energy \& Fuel Research Unit, The University of Auckland.

Aultman-Hall, L. (2004). A bicycle transportation primer; dispelling the myths and promoting the realities. ITE Journal on the Web, December, 2004.

Beckerman, B., Jerret, M., Brook, J., Verma, D., Arain, M., and Fikelsetin, M. (2008). Correlation of nitrogen dioxide with other traffic pollutants near a major expressway. Atmospheric Environment, 43, 275-290.

Bellman, R. (1958). On a routing problem. Quarterly of Applied Mathematics, 16, 87-90.

Boogaard, H., Borgman, F., Kamminga, J., and Hoek, G. (2009). Exposure to ultrafine and fine particles and noise during cycling and driving in 11 dutch cities. Atmospheric Environment, 43(27), $4234-4242$.

Boogaard, H., Janssen, N., Fischer, P., Kos, G., Weijers, E., Cassee, F., van der Zee, S., de Hartog, J., Meliefste, K., Wang, M., Brunekreef, B., and Hoek, G. (2012). Impact of low emission zones and local traffic policies on ambient air pollution concentrations. Science of the Total Environment, 435, 132-140.

Costello, S., Wang, J. Y. T., Dirks, K., Ehrgott, M., Salmond, J., and Etchebarne, J. (2012). Enabling sustainable transport planning decisions - linking transport and emissions models. Technical report, The University of Auckland.

De Bruin, Y., Carrer, P., Jantunen, M., Hanninen, O., di Marco, G., Kephalopoulos, S., Cavallo, D., and Maroni, M. (2004). Personal carbon monoxide exposure levels: contribution of local sources to exposures and microenvironment in milan. Journal of Exposure and Environmental Epidemiology, 14, 312-322.

de Hartog, J., Boogaard, H., Nijland, H., and Hoek, G. (2010). Do the health benefits of cycling outweigh the risks? Environmental Health Perspectives, 118(8), 1109-1116.

de Nazelle, A., Fruin, S., Westerdahl, D., Martinez, D., Ripoll, A., Kubesch, N., and Nieuwenhuijsen, M. (2012). A travel mode comparison of commuters' exposures to air pollutants in barcelona. Atmospheric Environment, 59, 151-159. 
Dirks, K. N., Johns, M. D., Hay, J. E., and Sturman, A. P. (2002). A simple semi-empirical model for predicting missing carbon monoxide concentrations. Atmospheric Environment, 36(3940), 5953 5959.

Dirks, K. N., Johns, M. D., Hay, J. E., and Sturman, A. P. (2003). A semi-empirical model for predicting the effect of changes in traffic flow patterns on carbon monoxide concentrations. Atmospheric Environment, 37(19), 2719 - 2724.

Dirks, K. N., Sharma, P., Salmond, J. A., and Costello, S. B. (2012). Personal exposure to air pollution for various modes of transport in Auckland, New Zealand. The Open Atmospheric Science Journal, 6, 84-92.

Duci, A., Chaloulakou, A., and Spyrellis, N. (2003). Exposure to carbon monoxide in the Athens urban area during commuting. The Science of the Total Environment, 309, 47-58.

Ehrgott, M., Wang, J. Y. T., Raith, A., and van Houtte, C. (2012). A bi-objective cyclist route choice model. Transportation Research Part A, 46(4), 652-663.

Götschi, T., Garrard, J., and Giles-Corti, B. (2015). Cycling as a part of daily life: A review of health perspectives. Transport Reviews. DOI:10.1080/01441647.2015.1057877.

Hatzopoulou, M. and Miller, E. (2010). Linking an activity-based travel demand model with traffic emission and dispersion models: Transport's contribution to air pollution in Toronto. Transportation Research Part D: Transport and Environment, 15(6), 315-325.

Hatzopoulou, M., Weichenthal, S., Barreau, G., Goldberg, M., Farrell, W., Crouse, D., and Ross, N. (2013). A web-based route planning tool to reduce cyclists' exposures to traffic pollution: A case study in montreal, canada. Environmental Research, 123, 58-61.

Int Panis, L., de Geus, B., Vandenbulcke, G., Willems, H., Degraeuwe, B., Bleux, N., Mishra, V., Thomas, I., and Meeusen, R. (2010). Exposure to particulate matter in traffic: A comparison of cyclists and car passengers. Atmospheric Environment, 44(19), 2263 - 2270.

Kaur, S., Niewwenheijsen, M., and Colville, R. (2005). Pedestrian exposure to air pollution along a major road in Central London, UK. Atmospheric Environment, 39, 3629-3641.

Lee, G., You, S., Ritchie, S., Saphores, J.-D., Sangkapichai, M., and Jayakrishnan, R. (2009). Environmental impacts of a major freight corridor. Transportation Research Record, 2123, 119-128. 
Liu, J.-J., Chan, C.-C., and Jeng, F.-T. (1994). Predicting personal exposure levels to carbon monoxide (co) in taipei, based on actual co measurements in microenvironments and a monte carlo simulation method. Atmospheric Environment, 28(14), 2361-2368.

Longley, I., Kingham, S., Dirks, K. N., Somerville, E., Pattinson, W., and Elangasinghe, A. (2013). Detailed observations and validated modelling of air quality impact of traffic on roadside communities: Final users' report. Technical report, New Zealand Transport Agency. Feb 2013. Report number: 516 ISBN 978-0-478-40725-9.

Martin, J. C., Milliken, D. L., Coob, J. E., McFadden, K. L., and Coggan, A. R. (1998). Validation of a mathematical model for road cycling power. Journal of Applied Biomechanics, 14, 276-291.

Medrano, F. A. and Church, R. L. (2015). A parallel computing framework for finding the supported solutions to a biobjective network optimization problem. Journal of Multi-Criteria Decision Analysis, 22(5-6), 244-259.

Mueller, N., Rojas-Rueda, D., Cole-Hunter, T., de Nazelle, A., Dons, E., Gerike, R., Gotschi, T., Int Panis, L., Kahlmeier, S., and Nieuwenhuijsen, M. (2015). Health impact assessment of active transportation: A systematic review. Preventive Medicine, 76, 103-114.

Müller-Hannemann, M. and Weihe, K. (2006). On the cardinality of the Pareto set in bicriteria shortest path problems. Annals of Operations Research, 147, 269-286.

Oja, P., Titze, S., Bauman, A., de Geus, B., Krenn, P., Reger-Nash, B., and Kohlberger, T. (2011). Health benefits of cycling: A systematic review. Scandinavian Journal of Medicine and Science in Sports, 21(4), 496-509.

Paix̃ao, J. M. and Santos, J. L. (2013). Labeling methods for the general case of the multi-objective shortest path problem - a computational study. In A. Madureira, C. Reis, and V. Marques, editors, Computational Intelligence and Decision Making, volume 61 of Intelligent Systems, Control and Automation: Science and Engineering, pages 489-502. Springer, Dordrecht.

Raith, A. and Ehrgott, M. (2009). A comparison of solution strategies for biobjective shortest path problems. Computers \& Operations Research, 36, 1299-1331.

Rank, J., Folke, J., and Jespersen, H. P. (2001). Differences in cyclists and car drivers exposure to air pollution from traffic in the city of Copenhagen. Science of the Total Environment, 1-3, 131-136. 
Schepers, P., Fishman, E., Beelen, R., Heinen, E., Wijnen, W., and Parkin, J. (2015). The mortality impact of bicycle paths and lanes related to physical activity, air pollution exposure and road safety. Journal of Transport \& Health. doi:10.1016/j.jth.2015.09.004.

Shekarrizfard, M., Valois, M.-F., Goldberg, M., Crouse, D., Ross, N., Parent, M.-E., Yasmin, S., and Hatzopoulou, M. (2015). Investigating the role of transportation models in epidemiologic studies of traffic related air pollution and health effects. Environmental Research, 140, 282-291.

Sider, T., Alam, A., Zukari, M., Dugum, H., Goldstein, N., Eluru, N., and Hatzopoulou, M. (2013). Land-use and socio-economics as determinants of traffic emissions and individual exposure to air pollution. Journal of Transport Geography, 33, 230-239.

Transport for London (2010). Travel in London Report 3. Technical report, Mayor of London. https://tfl.gov.uk/corporate/publications-and-reports/ travel-in-london-reports.

Wang, J. Y. T., Mirza, L., Cheung, A. K. L., and Moradi, S. (2014). Understanding factors influencing choices of cyclists and potential cyclists: A case study at the University of Auckland. Road and Transport Research, 23, 37-51.

Woodcock, J., Edwards, P., Tonne, C., Armstrong, B. G., Ashiru, O., Banister, D., Beevers, S., Chalabi, Z., Chowdhury, Z., Cohen, A., Franco, O. H., Haines, A., Hickman, R., Lindsay, G., Mittal, I., Mohan, D., Tiwari, G., Woodward, A., and Roberts, I. (2009). Public health benefits of strategies to reduce greenhouse-gas emissions: urban land transport. The Lancet, 374(9705), 1930-1943.

Woodcock, J., Tainio, M., Cheshire, J., O’Brien, O., and Goodman, A. (2014). Health effects of the london bicycle sharing system: Health impact modelling study. BMJ (Online), 348.

You, S., Lee, G., Ritchie, S., Saphores, J., Sangkapichai, M., and Ayala, R. (2010). Air pollution impacts of shifting freight from truck to rail at California's San Pedro Bay Ports. Transportation Research Record, 2162, 25-34.

Zuurbier, M., Hoek, G., van der Hazel, P., and Brunekreef, B. (2009). Minute ventilation of cyclists and bus passengers: an experimental study. Environmental Health, 8:48, 